\title{
Surgical management of hepatic hydatid cyst in children
}

\author{
Dinesh Prasad Koirala and A. K. M. Zahid Hossain
}

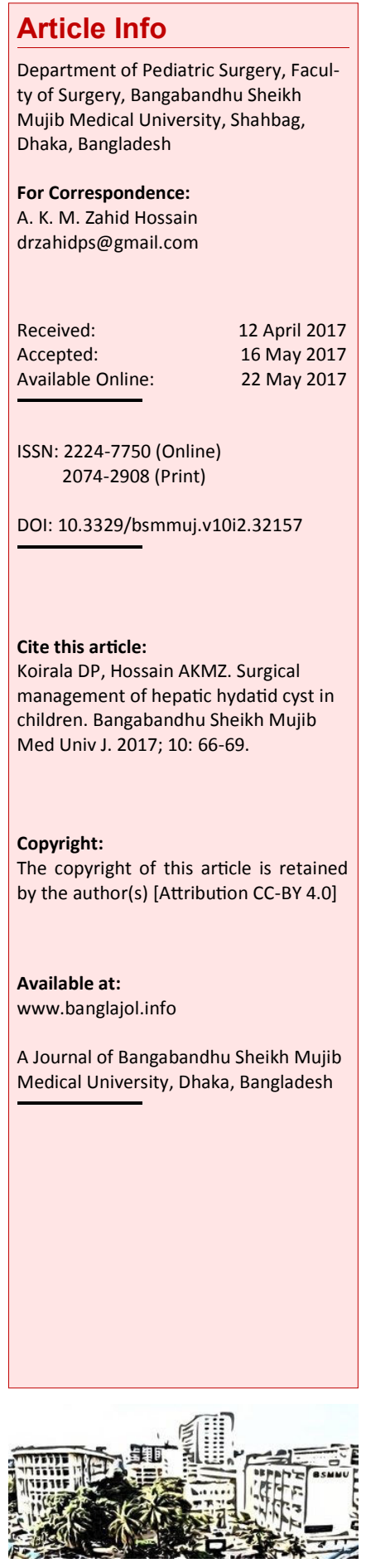

\section{Abstract}

The aim of this study was to demonstrate the surgical treatment and outcome of hydatid cyst in liver in children. The age of presentation varied from 8-11 years. All patients had abdominal pain, five had lump in right hypochondrium and three patients had fever. Hydatid cyst serology, indirect hemaglutination test, ultrasonography and CT scan were done in all the patients. Histological examination supported the diagnosis of hydatidosis since the cyst wall contains outer laminated and inner germinal layer. All the patients got relief of their preoperative symptoms after surgery. Two patients had positive serology after surgery. Therefore, they were given two additional regimen of albendazole and turned out to be serologically negative. In conclusion, hydatid cyst management in children is not consensual. However, conservative surgery remains the treatment of choice to avoid serious complication in the endemic region of Indian subcontinent.

\section{Introduction}

Hydatid cyst is a zoonotic disease caused by larval form of parasite of tapeworm mostly echinnococcus in human and many other mammals. It is characterized by world wide spread but is endemic mainly around Mediterian and Indian subcontinent. $\underline{1-3}$ The most common site of hydatid cyst is the liver $(60 \%)$, followed by lungs $(30 \%)$. The unusual sites are spleen, kidney, bone, thyroid, breast and pancreas. Human are incidental host who contact the disease by ingesting highly infective eggs of adult echinococcus harboring in small intestine of the definitive host like dogs and other canine animals. .4

The growth rate of hydatid cyst is very slow (3$5 \mathrm{~mm}$ /year). So, the patients remain asymptomatic for long time even 30-50 years. Hydatid cyst is not commonly presented in childhood. Due to delay presentation, hydatid cyst has become more challenging in pediatric group for the diagnosis and management by physicians. If liver hydatid cyst is left untreated, then it grows and follows one of several courses: develop fistula with adjacent organs or biliary system, rupture into peritoneal cavity seeding daughter cysts, and develop daughter cyst within or rarely die. But spillage in the abdominal cavity may lead to anaphylactic shock to the patient and leads to death. $\frac{5-7}{}$

This study was designed to analyze our conservative surgical treatment and outcome in children of endemic region of the third world with constraint resources.

\section{Materials and Methods}

The medical documents were reviewed retrospectively. The perioperative history of six patients was taken who underwent surgical conservative treatment of hydatid cyst of liver from January 2013 to August 2015. These patients were in regular follow-up. Patients were evaluated by the clinical presentation, laboratory investigation, imaging like chest X-ray, abdominal USG, CT scan, other organ involved, surgical intervention, length of the hospital stay, postoperative complications and followup.

Conservative surgical treatments were carried out in all the patients under general anesthesia. $20 \%$ hypertonic saline mixed with povidone iodine was introduced into the cyst. After 10 min, it was reaspirated and the incision was made over cyst. Hydectomy was done and the residual cavity was closed by capitonnage method i.e. obliteration of residual cyst cavity with transfixation sutures from depth to surface. Preoperative and postoperative sterilization with albendazole at the dose of $10 \mathrm{mg}$ per $\mathrm{kg}$ per day in two divided doses was done to every patient. 8

\section{Results}

A total of eight patients were reviewed who underwent conservative surgical treatment of hydatid cyst of the liver. The mean age of presentation was 5.5 years. Five were male and three were female. Six patients were 
Table I

\begin{tabular}{|c|c|}
\hline \multicolumn{2}{|c|}{$\begin{array}{l}\text { Epidemiological } \\
\text { characteristics }\end{array}$} \\
\hline Variables & 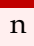 \\
\hline Gender & \\
\hline Male & 5 \\
\hline Female & 3 \\
\hline Symptoms & \\
\hline $\begin{array}{l}\text { Lump in right } \\
\text { hypochondrium }\end{array}$ & 6 \\
\hline Abdominal pain & 8 \\
\hline Fever & $J$ \\
\hline $\begin{array}{l}\text { CT scan; Involve- } \\
\text { ment of lobe }\end{array}$ & \\
\hline Right lobe & 0 \\
\hline Left lobe & 2 \\
\hline Both lobe & 2 \\
\hline
\end{tabular}

symptomatic and two patients were diagnosed incidentally (Table I). The presenting complains were mass in the right hypochondrium and abdominal pain. The duration of symptoms was from 1-1.5 years.

Hydatid cyst serology was positive in six patients and negative was found in two patients. Indirect hemaglutination test was done in all the patients. There was no significant finding in the plain $x$-ray abdomen which was done in all patients. Ultrasonography and CT scan of abdomen were implemented in all the patients (Figure 1).9-10 The mean cyst diameter was $6.8 \mathrm{~cm}$ (range $5-11 \mathrm{~cm}$ ). In two patients, two different cysts were found in the right lobe and left lobe measuring about $8.2 \mathrm{~cm}$ and 10.1 $\mathrm{cm}$. In one patient, the cyst was present both in the right lung and liver. Cyst from the lung was treated by the same conservative surgical method by thoracic surgeon. The cyst from the liver was treated by us at the interval of three months apart. The most common radiological finding was hepatomegaly. The location of cyst was mostly in the right lobe whereas two patients have involvement in the both right and left lobes of the liver. Histological examination supported the diagnosis of hydatidosis since the cyst wall contains outer laminated and inner germinal layer.

Conservative surgical treatment was done in all the patients (Figure 2) after sterilization with albendazole at the dose of $10 \mathrm{mg}$ per $\mathrm{kg}$ per day at two divided doses for three weeks. 11 Albendazole was given two weeks before the surgery. The range of hospital stay was from 5-15 days. Perioperative period was uneventful. Albendazole was given to all the patients for three weeks after operation. Four patients turned out to be serologically negative and two were positive. Those patients were indicated one more cycle of albendazole for three weeks after free period of drug for two weeks. Finally those patients also turned out to be serologically negative. The follow-up were made at three months, six months and yearly. We followed the patient regularly with physical examination, serological and abdominal ultrasonography. There is no recurrence till date.

\section{Discussion}

Children remain mostly asymptomatic even if the infection is acquired in early childhood. The cyst grows slowly at a rate of $3-5 \mathrm{~mm}$ per year. $\underline{12,13}$ Children present with painful left upper abdominal mass when the cyst attains a considerable size. The differential diagnosis includes epidermoid cyst, cystic lymphangioma or hemangioma, splenic abscess or hematoma. To aid in diagnosis specific laboratory tests like indirect hemagglunitation, complement fixation test and indirect immune fluorescence. There are different modalities of treatment for the hydatid cyst of liver depending on different settings.14-16 In centers with special interest and resource rich environments, patient benefits from an exceptional concentration of clinical experiences and advanced technology and treatment facilities, whereas in endemic regions of the third world with constrained resources, choice of treatment modalities are limited.

The goal of the surgery in hydatid cyst is inactivation of the cestode, parasite evacuation from the cyst cavity, removal of germinal layer and obliteration the residual cavity. $\underline{17}$ Surgical interventions consist of conservative, radical and laparoscopic approaches. Conservative technique involves simple tube drainage marsipulization (i.e. surgical exteriorization of a cyst by resection of anterior wall

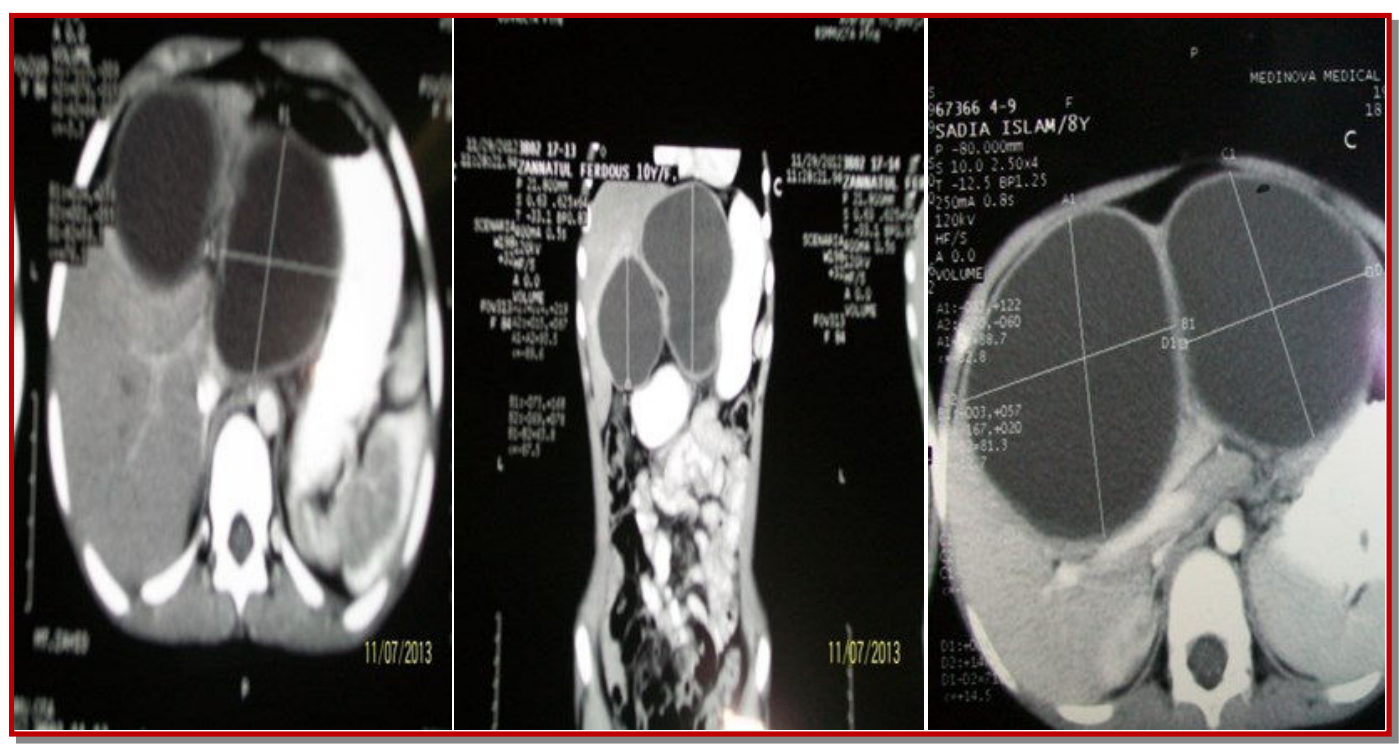

Figure 1: CT scan showing hepatic hydatid cyst, cyst within cyst 


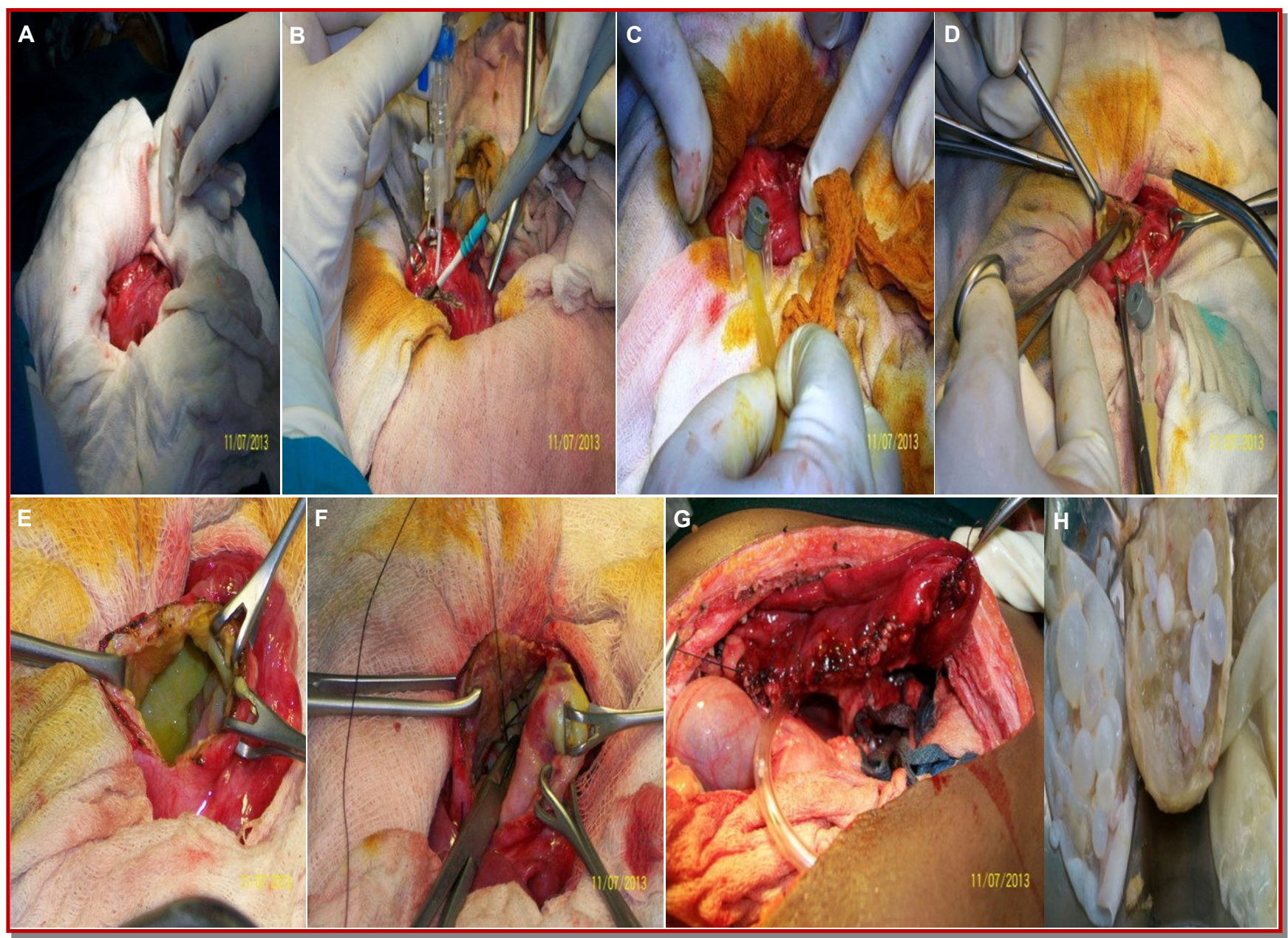

Figure 2: Surgical steps. A) Meticulous packing with hypertonic saline; B) Instillation; C) Reaspiration scolicidal; D) Evacuation of the cyst content leaving the E) Pericyst; F) Residual pericyst was managed by G) Captionnage; H) Cyst attached to the liver

and suture of the cut edges of the skin, thereby establishing a pouch of what was formally an enclosed cyst), captionnage, deroofing, partial simple cystectomy or open or closed total cystectomy with or without omentoplasty. Radical procedures include the total pericystectomy, partial hepatictomy or lobectomy. A benzimidazole agent is best used before any surgery in an attempt to sterilize the cyst content and reduce the risk of anaphylaxis and dissemination. $\underline{18-19}$

Operative field is meticulously packed for the conservative surgical treatment. This is done by mobs soaked with the solutions that kill the infective scoleces and protoscolices of the parasite residing within hydatid cyst, or potentially leak from the cyst during surgical manipulation. Then introduction of the solutions in the cyst itself and respirations after $10 \mathrm{~min}$ further aid in killing the scoleces. Various scolicidal solutions that can be used are $20 \%$ hypertonic saline, povidone iodine, hydrogen peroxide, iodine formalin, silver nitrate, albendazole. 19 The use of alone or in combination of these scolicides is found to be useful. After hydec- tomy cyst content is evacuated. The remaining cavity is irrigated with scolicidal agent and is explored for any possible communication with bile duct. If any bile leakage is found, then the offending bile duct is sutured. The cyst cavity is, then, drained and obliterated. Obliteration is done by captionage. After placing a drain into the sub hepatic space abdomen is closed in layers.

Complication of hepatic hydatid cyst may include the postoperative hemorrhage, bile exudation from the residual cyst cavity, incision fistula formation, cholangitis, wound infection, sepsis, incisional fistula, and pulmonary complications such as pneumonia and pulmonary embolization. $\underline{20}$ No morbidities were found in our patients after surgery. Two patients were serological positive even after surgery. They turned out to be negative after two cycles of albendazole which was not required in four patients.

The sample size may be small for making a conclusion of treatment. However, looking at the rarity of the disease in children and challenges in 
diagnosis, this study will help to provide a perspective in the management of hydatid cyst in the endemic region of the Indian subcontinent.

\section{Conclusion}

Hydatid cyst management in children is not consensual. However, the conservative surgical treatment for hydatid cyst of liver can be performed in children with less morbidity and better outcome.

\section{References}

1. Atmatizidis KS, Pavlidis TE, Pappayiorgas BT, Mirelis C, Papaziogas TB. Recurrence and longterm outcome after open cystectomy with omentoplasty for hydatid disease in endemic area. Acta Chir Belg. 2005; 105: 198-202.

2. Agarwal S, Sikora SS, Kumar A, Saxena R, Kapoor VK. Bile leaks following surgery for hepatic hydatid disease. Indian J Gastroenterol. 2005; 24: 55-58.

3. Anand S, Rajagopalan S, Mohan R. Management of liver hydatid cyst: Current perspective. Med J Arm Force India. 2012; 68: 304-09.

4. Dawson JL, Stamatkis JD, Stringer MD, Williams R. Surgical treatment of hepatic hydatid disease Br J Surg. 1988; 75: 946-50.

5. Angelica MD, Fong Y. The liver. In: Sabiston Textbook of surgery. $18^{\text {th }}$ ed. Saunders, 2007, pp 1494-96.

6. Aradkeh S, EL-Muhtaseb H, Farah G. Predictors of morbidity and mortality in the surgical management of hydatid cyst of liver. Langenbecks Arch Surg. 2007; 392; 35-39.

7. Eckert J, Gemme MA, Meslin F-X Pawlowski Zs (eds). WHO/OIE manual on Echinococcus in humans and animals public health problem of global concern. Geneva, 2001.

8. Talaiezadeh A, Maraghi SH. Hydatid disease in children: A different pattern than adults. Pakistan J Med Sci. 2006; 22: 329-32.
9. Franci C, Di Vico B, Teggi A. Long-term evaluation of patient with hydatid cyst treated with benzimidazole carbamates. Clin Infect Dis. 1999; 69; 304-09.

10. Giorgio A, Disarno A, Giorgio S, et al. Percutaneous treatment of hydatid liver cyst. Recent Pat Anti-infect Drug Discov. 2009; 4: 29 36.

11. deDiegoj, Lecumberri FJ, Franquet T, Ostiz S. Computed tomography in hepatic echinococcus. Am J Roentgenol. 1982; 139; 699-702.

12. Malik AA, Bari SUL, Amin R, Jan M. Surgical management of complicated hydatid cyst of liver. World J Gastrointestinal Surg. 2010; 27: 7884.

13. Smego RAJr. Sebango P. Treatment options for hepatic cyst echinococcosis. Int J Infect Dis. 2005; 9: 69-76.

14. Rattan KN, Sharma A. Hydatid disease in children. Indian J Chest Dis Allied Sci. 1998; 40; 73-77.

15. Huizinga Wkj, Grant CS, Daar As. Hydatid disease, Wood WC (eds). In: Textbook of surgery. $2^{\text {nd }}$ ed. New York, Oxford University Press, 2000, pp 3298-330.

16. Sayek I, Timaksiz MB, Dogan R. Cystic hydatid disease: Current trends in diagnosis and management. Surg Today. 2004; 34: 987-96.

17. Seven R, Berber E, Mercan S, Eminoglu L, Budak D. Laparoscopic treatment of hepatic hydatid cysts. Surgery 2000; 128; 36-40.

18. Taylor BR, Langer B. Current surgical management of hepatic cyst disease. Adv Surg. 1997; 31: $127-48$.

19. Saremi F. Percutaneous drainage of hydatid cyst; use of cutting device to avoid leakage. Am J Surg. 2002; 184: 63-69.

20. Kayaalp C, Bzeizi K, Demirbag AE, Akoglu M. Biliary complications after hydatid liver surgery: Incidence and risk factors. J Gastrointest Surg. 2002; 6: 706-12. 